University of Wollongong

Research Online

Faculty of Engineering - Papers (Archive)

Faculty of Engineering and Information

Sciences

2002

\title{
Thermal and electrical characteristics of a multilayer thermionic device
}

B. C. Lough

University of Wollongong

S. P. Lee

University of Wollongong

Z. Dou

University of Wollongong

R. A. Lewis

University of Wollongong, roger@uow.edu.au

C. Zhang

University of Wollongong, czhang@uow.edu.au

Follow this and additional works at: https://ro.uow.edu.au/engpapers

Part of the Engineering Commons

https://ro.uow.edu.au/engpapers/50

\section{Recommended Citation}

Lough, B. C.; Lee, S. P.; Dou, Z.; Lewis, R. A.; and Zhang, C.: Thermal and electrical characteristics of a multilayer thermionic device 2002.

https://ro.uow.edu.au/engpapers/50

Research Online is the open access institutional repository for the University of Wollongong. For further information contact the UOW Library: research-pubs@uow.edu.au 


\title{
THERMAL AND ELECTRICAL CHARACTERISTICS OF A MULTILAYER THERMIONIC DEVICE
}

\author{
B. C. C. Lough*, S. P. Lee, Z. Dou, R. A. Lewis, and C. Zhang \\ Institute of Superconducting and Electronic Materials, \\ University of Wollongong, Ncw South Wales, 2522, Australia. \\ *Email Address: bclol (ajuow.cdu.au
}

\begin{abstract}
We report our recent experimental and numerical investigation into the thental and electrical transport in GaAs-AlGaAs semiconductor multilayer structures. Electrical and thermal conduction measurements were performed on multilayer structures to determine the temperature gradient across the sample. AuGe was used for top contact metallisation, and an InGa cutcctic for bottom substratc contact. Metallisation contacts were also grown directly onto the substrate in order to compare results with and without the device included. By using a variable load resistor connected in series with the device, we can accurately determine the current-voltage characteristics of the device. Thus the power imput can be obtaincd. The temperature distribution on the top and bottom substrate was measurcd with micro thermocouples. Since the cooling device is grown on an n-type semiconductor substrate the effects of joule heating in the substrate had to be considered. Treating the substrate as bulk material and calculating joule heating showed that this effect is negligible. Comparing experimental measurements of the device and of the substrate alone support this. The experimental I-V characteristics of the device differ significantly in shape from theorctical $I-V$ characteristics. This may be due to that fact that space-charge effects are not included in the currently acecpted model (Richardson's equation). Duc to the small size of the devices and therefore very large electric fields, this effect may be important. Work is currently being carried out to modify the model. The devices studied so far have been made from undoped $\mathrm{GaAs}-\mathrm{Al}_{0.07} \mathrm{Ga}_{0.03}$ As heterostructures. For large cooling power it is a requirement that the conduction band of the layers be close to the Fermi level.
\end{abstract}

\section{INTRODUCTION}

The simplificd cquations used to describe the clectronic transport in the thermionic devices are based upon Richardson's cquation. We have shown that although not necessarily more efficient than a single-barricr device, multibarrier devices are capable of delivering much more cooling power [1]. Referring to Fig. 1, the net electrical current leaving the $i_{t h}$ electrode of an $N$-barrier device under an applied bias $\delta V$ is given by:

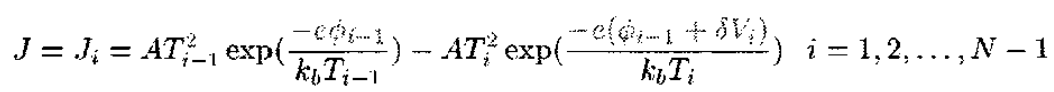

where $A$ is Richardson's constant given by:

$$
A=\left(e m^{*} k_{B}^{2}\right) /\left(2 \pi^{2} h^{3}\right) \simeq 120 \mathrm{~A} / \mathrm{cm}^{2} \mathrm{~K}^{2} .
$$

The other variables are defincd as:

$$
\begin{array}{ll}
\phi_{i}=\text { Height of } i_{t h} \text { barrier }(\mathrm{eV}) ; & T_{i}=\text { Temperature of } i_{t h} \text { electrod } \\
\delta V_{i}=\text { Potential drop across } i_{t} h \text { barrier }(\mathrm{V}) ; & k_{b}=\text { Boltzmann's constant; } \\
e=\text { Charge of clcctron: } & m^{*}=\text { Elcctron cffective mass; }
\end{array}
$$

Eq. 1 is quite simplistic in that it assumes constant temperature and potential in each of the electrodes, which is incorrect for a real device. It also assumes that there is no space charge collection at the heterostructure interface. Fig. 1 shows the conduction band diagram for such an ideal device. The clectrode (or bottom of the potential barrier) is the Fermi energy in the electrode material (GaAs), whilst the top of the barrier is the conduction band in the barrier material $\left(\mathrm{Al}_{0.07} \mathrm{Ga}_{0.03} \mathrm{As}\right)$. 


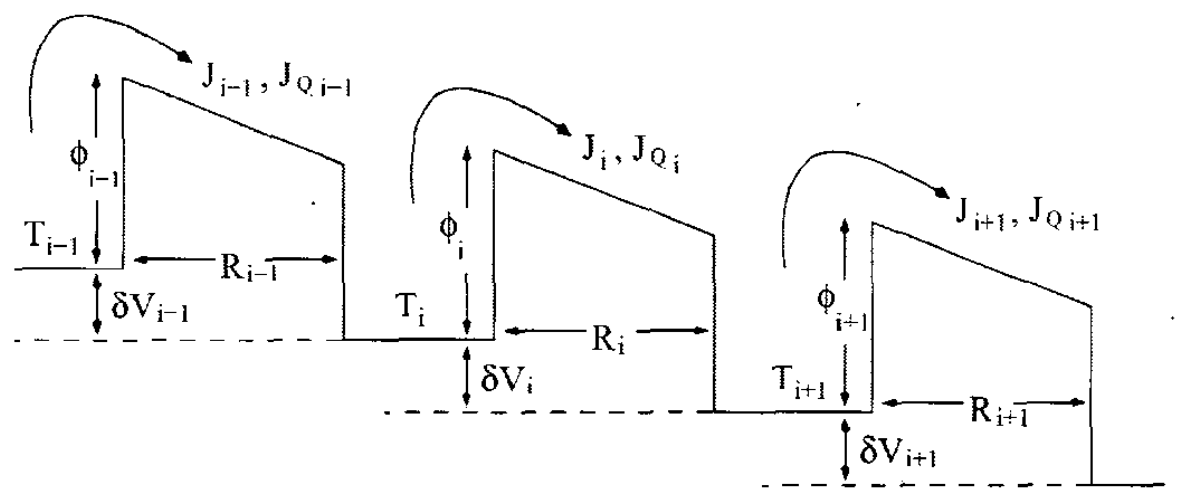

Figure 1: Energy-band diagram of 'Ideal' Multibarrier Thermionic Cooler

\section{DEVICE STRUCTURE}

The devices discussed in this paper were grown on a $450 \mu \mathrm{m}$ thick GaAs wafer with an impurity concentration of $2 \times 10^{18} \mathrm{~cm}^{-3}$. A buffer layer of $100 \mathrm{~nm} \mathrm{n}{ }^{+} \mathrm{GaAs}$ was grown before 10 alternating layers of undoped GaAs$\mathrm{Al}_{0.07} \mathrm{Ga}_{0.93} \mathrm{As}$ each of $50 \mathrm{~nm}$. The devices were grown by the Australian National University. Because of some design flaws, no cooling has been observed in the samples. On analysis of the data. this result is in agreement with theory. The main reason for no observed cooling is because of the use of undoped material for the device. For high cooling power, it has been shown that the barricr heights at room temperature must be less than $300 \mathrm{meV}$ [2]. In our samples this value is even lower, due to the thermal resistance of the materials used. Referring to Eq. 3 and Eq. 4, a low thermal resistance lowers the net energy current achievable for a device. The conduction band offset between materials was designed to be $\sim 75 \mathrm{meV}$. A barrier height of $75 \mathrm{meV}$ will theoretically produce measurable cooling at room temperature. Unfortunately, because of the use of undoped material, the conduction band edge of the clectrodes sits at $\sim 150 \mathrm{mcV}$ above the Fermi cnergy. This gives an effective barricr height of $\sim 225 \mathrm{mcV}-$ too large to achieve any appreciable cooling at room temperature. Regardless of this, it is still beneficial to model the I-V characteristics of the device. By doing so, it is possible to see how well equation Eq. 1 does model real devices.

\section{IDEAL DEVTCE EQUATIONS}

In addition to the clectric current equation described in Eq. 1 there are two encrgy current equations that must be solved. Assuming net heat current flow is from left to right in Fig. 1, the energy current entering the $\hat{t}$ th clectrode (from the left) is given as

$$
\begin{aligned}
J_{Q i}^{i n}= & \left(\phi_{i-1}+\delta V_{i}+\frac{2 k_{b} T_{i-1}}{c}\right) A T_{i-1}^{\prime 2} \exp \left(\frac{-e \phi_{i-1}}{k_{b} T_{i-1}}\right) \\
& -\left(\phi_{i-1}+\delta V_{i}+\frac{2 k_{b} T_{i}}{e}\right) .4 T_{i}^{2} \exp \left(\frac{-\varepsilon\left(\phi_{i-1}+\delta V_{i}\right)}{k_{b} T_{i}}\right) \\
& \frac{T_{i}-T_{i-1}}{R_{i}} \quad i=1,2, \ldots, N \cdots-1
\end{aligned}
$$

and the energy current leaving the the electrode (to the right) is given as

$$
\begin{aligned}
y_{Q i}^{\text {wut }=} & \left(\phi_{i}+\frac{2 k_{b} T_{i}}{e}\right)-4 Y_{i}^{2} \exp \left(\frac{e \phi_{i}}{k_{b} T_{i}}\right) \\
& -\left(\phi_{i}+\frac{2 k_{b} T_{i}+1}{e}\right) A T_{i+1}^{2} \exp \left(\cdots-\frac{-\varepsilon\left(\phi_{i}+\delta V_{i+1}\right)}{k_{b} T_{i+1}}\right) \\
& -\frac{T_{i+1}-T_{i}}{R_{i+1}} \quad i=1,2, \ldots, N-1
\end{aligned}
$$

where $R_{i}$ is the thermal resistivity of the $i$ th barricr.

For continuity of energy current, $J_{Q:}^{y_{2}}=J_{Q i}$ ralt

NOTE: $J_{Q i}^{i n}-J_{Q(i-1)}^{o u t}=\delta V_{i} J \neq 0$, where $\delta V_{i} J$ is the work needed to produce cooling across the $i^{\text {th }}$ barrier. 


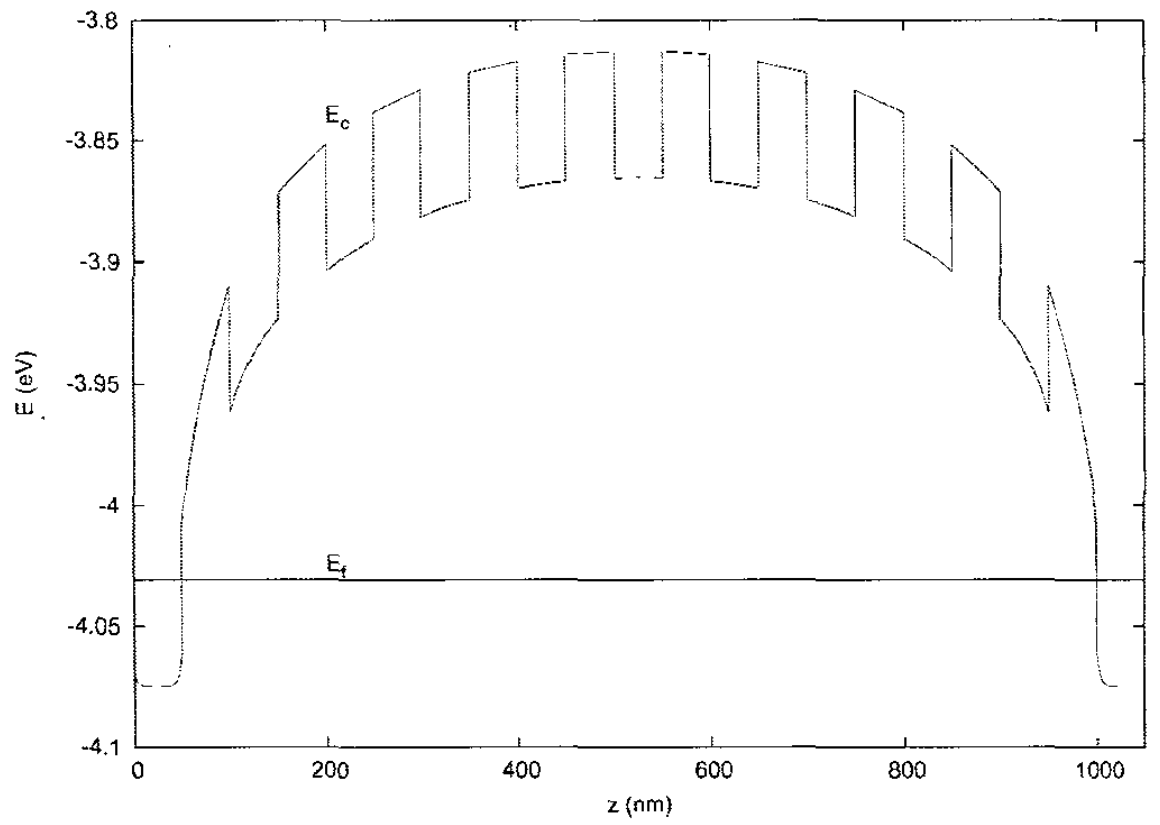

Figure 2: Encrgy-band diagram of multibaricr thermionic cooler calculated using Poisson's equation (400 $\mu \mathrm{m}$ substrate not included).

Equations 1, 3 and 4 are solved in order to preserve electric and energy current continuity. They are used to calculate the I-V characteristics of the device. In a recent paper we have discussed the difference between the experimental I-V characteristics and the ones given by the above equations [3]. It was noted that space charge accumulation is not accounted for in the above cquations. Because of the small geometry of the device (barrier widths of $\sim 50 \mathrm{~nm}$ ), large electric ficlds can be set up. As a result, the space charge potential between electrodes can become important. Under certain circumstances, this potential can be approximated very accurately by image force lowering [4]. When this approximation was used, the theoretical I-V characteristics of the devices did come closer to those obtained from experiment, but this new term does not sufficiently explain the discrepancy. In order to develop the theoretical model further, we have used first principles to first calculate the 'real' band structure of the device via Poisson's Equation.

\section{FIRST PRINCIPLES APPROACH}

Fig. 2 shows the energy band diagram for the first-generation devices calculated using Poission's Equation:

$$
\nabla \cdot\left[\epsilon_{s}(z) \nabla \phi(z)\right]=\rho(z)
$$

where the position-dependent variables are defined as:

$$
\epsilon_{*}(z)=\text { Permittivity of material; } \quad \phi(z)=\text { Electrostatic potential; } \quad \rho(z)=\text { Charge concentration; }
$$

The equation was solved numerically using an array of points spaced sufficiently to allow convergence. Because of the geometry of the device, the equation only needs to be solved in 1-D. It is immediately obvious that this method will represent the device better than the idcalised cquations of the previous section. Fig. 2 shows that band-bending due to charge accumulation is a very important factor that must be taken into consideration. Solving the electrical transport equations via this method is advantageous in that space-charge effects do not need to be included explicitly in the equations. They are an inherent part of the system as long as Eq. 5 is satisfied. The band diagram in Fig. 2 shows that the conduction band in the barrier material is around $225 \mathrm{mcV}$ above the Fermi energy in the electrode material, giving an effective batricr height of the same size.

\section{RESLLTS AND ANALYSIS}

The theoretical I-V characteristics of the devices were calculated using the freeware computer program SimWindows.32. This program calculates properties of semiconductor devices via an input file giving the device structure. Fig. 3 shows both the theoretical and experimental I-V characteristics of one of the devices. The results shown 


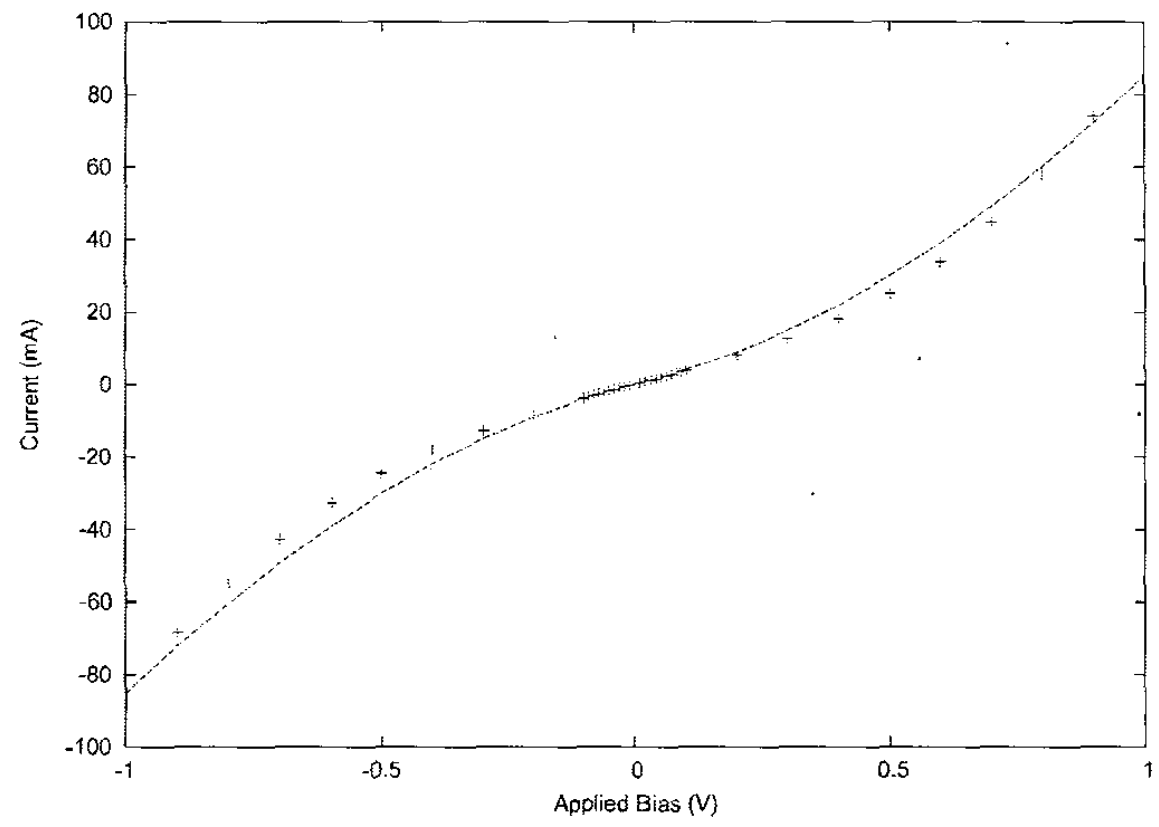

Figure 3: Experimental (+) and Theorctical (-) I-V characteristics

are for a device with a $3 \mathrm{~mm}$ radius. As can be seen from the figure, there is very close agrecment with the experimental results. There are two major factors which explain why no cooling was observed in the devices. The first, as already discussed, is that the effective barrier height of the structure is close to $225 \mathrm{meV}$. For the material that we used to produce the samples (GaAs), this barrier height needs to be significantly lower in order for there to be sufficient power to achicve cooling at room temperature. The sccond factor, perhaps more important than the first, has to do with the actual structure of the device. For efficient cooling via thermionic transport, electrons must be able to travel ballistically across the potential barrier. For this to occur, the barrier width must be less than the mean free path for electrons. Typically, this value is $\sim 50-100 \mathrm{~nm}[5]$. Referring to Fig. 2 , from the point of view of electrons at the Fermi energy, the device structure can be approximated by a single potential barrier of height $225 \mathrm{mcV}$. This means that the transport will not be ballistic and there may be considerable scattering. Once again, this is may be overcome by using doped material.

\section{CONCLUSION}

Because of some fundamental design flaws in these devices - namely, the use of undoped material - no cooling was observed. New devices have been made to remedy this, and device characterisation is currently being carried out. The results show that space-charge effects are very important in these devices (because of the high electric fields due to small device geometry) and should be included in any analysis of the devices. By using numerical techniques to solve Poisson's Equation and to calculate current under non-equilibrium conditions, these offects are included and give good agreement with experimental data.

Acknowledgement: This work is supported in part by the Australian Research Council and Email Ltd.

\section{REFERENCES}

[1] B. C. Lough, S. P. Lee, Z. Dou, R. A. Lewis, C. Zhang. Multilayer thermionic cooling in semiconductor heterostructures, Australian Institute of Physics 15th Biennial Congress 2002 Proceedings. In Print.

[2] G. D. Mahan, Thermionic Refrigeration, J. Appl. Phys. 76, 7 (1994).

[3] B. C. Lough, S. P. Lee, Z. Dou, R. A. Lewis, C. Zhang, Investigation into space charge effects in I-V characteristics of multi-layer semiconductor thermionic devices, International Conference on Superlattices, NanoStructures and Nano-Devices 2002 Conference Procecdings. In Print.

[4] J. B. Scott, Extension of Langmuir space-charge theory into the accelerating field range, J. Appl. Phys. 52, 7 (1981).

[5] G. D. Mahan, J. O. Sofo, M. Bartkowiak, Multilaver thermionic refrigerator and generator, J. Appl. Phys. 83, $9(1998)$. 